\title{
Turismo en la localidad de Santa Fe a través del diseño y desarrollo de una aplicación móvil implementando la realidad aumentada*
}

\begin{abstract}
Tourism in the Santa Fe locality across the design and mobile application development implementing the augmented reality
\end{abstract}

Christian Fabián Martínez Camargo**

Wilson Javier Rivera Barreto***

Como citar este artículo

Martínez, C; y Rivera, W. (2019). Turismo en la localidad de Santa Fe a través del diseño y desarrollo de una aplicaión móvil implementando la realidad aumentada. Designio. Investigación en diseño gráfico y estudios de la imagen 1(1), pp. 4374. Recuperado a partir de http://cipres.sanmateo.edu.co/index.php/designio

\footnotetext{
*Este artículo es resultado del trabajo de grado titulado Turismo en la localidad de Santa Fe a través del diseño y desarrollo de una aplicación movil implementando la realidad aumentada. (Profesional). Facultad de Ingenierías y Afines. Fundación Universitaria San Mateo.

${ }^{* *}$ Fundación Universitaria San Mateo. Correo electrónico: cfmartinez@sanmateo.edu.co

***Fundación Universitaria San Mateo. Correo electrónico: wjrivera@sanmateo.edu.co
} 
Resumen En Bogotá D.C. está ubicada la localidad de Santa Fe, un distrito reconocido por ser uno de los centros culturales más importantes de la ciudad. Con los años, se ha convertido en el hogar de diversos lugares culturales y una importante atracción turística. Este proyecto se centra en proporcionar a los visitantes del distrito una experiencia más dinámica, utilizando herramientas tecnológicas innovadoras como la realidad aumentada (RA). En vista de su valor histórico y atractivo turístico, fueron elegidos cinco de los lugares más visitados en esta localidad para implementar este proyecto. El objetivo es aumentar el impacto de estos lugares en la memoria de los visitantes, fortalecer y promover el turismo en Bogotá, poniendo a disposición una aplicación móvil interactiva que sea fácil de usar y que presente la información a los visitantes con un aspecto atractivo. Este proyecto presenta las etapas en el proceso de diseño y desarrollo de la aplicación: dibujo, desarrollo de modelos 3D, integración de elementos en Unity, programación y compilación.

Palabras clave turismo; realidad aumentada; Bogotá; Santa Fe; aplicaciones móviles; android. 
Abstract In Bogotá D.C. is located Santa Fe, a district (and a locality) recognized for being one of the most important cultural centers in the city. Over the years, this area has become the home of diverse cultural places and an important tourist attraction. This project is focused on providing, to the district visitors, a better way for a dynamic experience, using innovative technology tools such as the augmented reality. Considering their historical value and tourist appeal, five of the most visited places in this area were chosen to implement this project. The aim is to increase the impact of these places in the memory of visitors, to strengthen and promote tourism in Bogotá by making available an interactive mobile application, easy to use and that presents to visitors the information with an attractive look and feel. This project presents the stages in the process of design and development of the application: the sketching, the development of 3D models, the integration of elements in Unity, the programming and the compilation.

Keywords tourism; augmented reality; Bogotá; mobile applications; android; Santa Fe. 


\section{Introducción}

Uno de los sectores económicos fuertes para el desarrollo de un país, está relacionado con el turismo y la cultura; impulsando al progreso, crecimiento y empleo que generan beneficios en sus bienes y servicios. De tal forma la industria turística inicia un fortalecimiento en cuanto a sus herramientas de información y comunicación por medio de tecnologías implementadas en algunos lugares del mundo, como la innovadora exposición en realidad aumentada. En este caso, el turista tiene la facilidad, a través de sus dispositivos móviles, de iniciar una interacción guiada sobre los puntos de interés a través de información que encuentra en imágenes o textos. Así, la experiencia del usuario se convierte en algo dinámico, atractivo, impactante y diferente, de acuerdo con la manera tradicional en que suelen realizarse los recorridos en el lugar visitado.

En este sentido, esta investigación se enfoca en el desarrollo de una aplicación para dispositivos móviles que utilice la realidad aumentada. Con esta se pretende brindar información al turista o usuario, además de promover los sitios de interés específicamente ubicados en la localidad de Santa Fe de la ciudad de Bogotá D.C., entre la Calle 39 y la Calle 13, de igual forma entre la Carrera 14 (Av. Caracas) y los cerros orientales donde se encuentra el Santuario de Monserrate. Algunos de los lugares que se desean dar a conocer por medio de la aplicación son: el Mirador de la Torre Colpatria, el Museo Nacional de Colombia, el Museo del Oro,

el Planetario Distrital de Bogotá y la Basílica del Señor Caído de Monserrate. Los espacios serán presentados de forma tridimensional así como el mapa del área antes mencionada. De igual forma se va a crear un personaje guía con el cual 
el visitante o turista podrá interactuar con el fin de ubicar el lugar que sea de interés.

Frente a lo anterior, es importante que la elección del proyecto y su enfoque en la utilización de la realidad aumentada se encuentra motivada por el aporte que pueda brindar al turismo en los lugares seleccionados de la localidad. Hasta el momento no se ha creado una interacción diferente para el turista relacionada con esta innovadora herramienta tecnológica.

Por otra parte, el presente artículo da a conocer el proceso con el cual fue desarrollada la aplicación. Aquí cabe resaltar la importancia de los modelados tridimensionales del terreno anteriormente delimitado y de los lugares de interés turístico-cultural por medio del Software Autodesk Maya, así como su correspondiente integración con Unity y Vuforia.

Finalmente, se espera de esta investigación que a partir de la construcción de la aplicación, con la utilización de realidad aumentada, se genere una mejor experiencia en los usuarios o turistas y que encuentren una forma novedosa de reconocimiento y aprendizaje sobre los sitios mencionados.

La realidad aumentada se ha convertido en una herramienta importante en muchos campos del conocimiento a nivel mundial. A nivel cultural resulta ser de gran ayuda para el usuario, permite un aprendizaje más dinámico y atractivo con la presentación de diferentes contenidos. Según lo anterior, se mencionan algunos antecedentes de realidad aumentada a nivel mundial, nacional y local, evidenciando a su vez la evolución que ha tenido esta tecnología a través del tiempo. 
Antecedentes internacionales

Desde el 2008 hasta la actualidad, los estudios de la tecnología en realidad aumentada se han dedicado a la interacción con móviles en pequeño formato, consiguiendo más rapidez y reduciendo el consumo de memoria. En este sentido, la empresa Mobilizy lanzó al mercado una nueva aplicación, que consistía en una brújula digital, sensores de orientación, acelerómetro, mapas y videos con contenidos de Wikipedia, Ilamada Wikitude; caracterizada por la superposición de información en tiempo real a la imagen capturada por la cámara. Esta funcionaba como una guía de viajes para la obtención de información turística para los usuarios (Ruiz Torres, 2013, pág. 48).

Wikitude pretendía facilitar a los usuarios la búsqueda sobre sus lugares de interés solo con digitar el nombre de dicho lugar. Posteriormente se visualizaba en la pantalla del dispositivo la información del sitio por medio de etiquetas virtuales que indicaban horario, precios. En el caso de museos, imágenes, historia, obras y otra información de interés adicional respecto al sitio (Ruiz Torres, 2013)

Más adelante, en el año 2009, SPRXmobile desarrolló una aplicación aún más avanzada denominada Layar. Para este caso, el servidor disponía de información obtenida de buscadores web tales como Wikipedia, Twitter, Brightkite, contenido sobre guías de viaje, cultura, naturaleza etc. En este sentido, con respecto a la aplicación, se hace referencia a lo siguiente: "Desde la web de Layar, es posible descargar los mapas e información de los destinos turísticos que queramos visitar de una forma totalmente gratuita y así poder tener toda la información de una guía de viajes en nuestro dispositivo a través de la conexión a internet" (Ruiz Torres, 2013, pág. 48). 
Por su parte, David Ruiz Torres (2013), menciona algunos destinos turísticos que han sido presentados a través de guías en realidad aumentada, por ejemplo, la aplicación de Layar con la Diputación de Huesca en España. De igual forma, aplicaciones como Las Rutas Culturales de Andalucía (España) en el año 2012, la cual permite ser descargada gratuitamente en dispositivos portables. De esta manera da a conocer información de distintas ciudades con sus respectivos monumentos, yacimientos arqueológicos, museos, hoteles, gastronomía entre otros (Ruiz Torres, 2013).

Asimismo, surge una propuesta de nuevas técnicas en realidad aumentada para el turismo, expuesta por un grupo de investigadores de la universidad de Málaga en España en el año 2014. En esta, aparte de ofrecer los servicios de localización y búsqueda de preferencias al turista, se integran los sistemas de recomendación. Los miembros de un grupo con perspectivas turísticas afines, pueden brindar sus recomendaciones sobre puntos de interés a otros usuarios. Para ello, los investigadores José L. Leiva, Antonio Guevara, Carlos Rossi y Andrés Aguayo (2014), quienes generaron la propuesta, refieren que el sistema de recomendación orientado al turismo debe cumplir con los siguientes factores en la arquitectura del sistema propuesto:

- Estructura de almacenamiento para los gustos, preferencias y descripción de los sitios turísticos.

- Tener en cuenta las preferencias del grupo, pues la mayoría de las veces el turismo se realiza en grupo.

- Disponer de una valoración para cada punto que se visite.

- La información debe tener en cuenta la información contextual. 
También se resaltan proyectos como Tierra de Gigantes creado en el año 2014, por un grupo de estudiantes del Centro Educativo IES Isabel Perillán y Quiroz. Su objeto residía en mejorar la accesibilidad en la información turística, mediante una aplicación móvil en realidad aumentada que la haga más interactiva y llamativa, para visitantes del Campo de Criptana ciudad Real (Municipio español). De igual forma, esta aplicación abre la posibilidad de introducir no solo una comunicación visual con imágenes en la geografía e historia, sino que además posibilita la traducción en diferentes idiomas para que sea más amplio el campo de turismo (Centro Educativo IES, 2015).

Por otro lado, el patrimonio de la ciudad de Salamanca, España, (que se remonta en la época de la edad de hierro) presenta su contenido histórico y muestra cultural, por medio de realidad aumentada implementada en un software SNPM-RA (protocolo simple de administración de red) con modelos 3D, audio, texto y video de cada punto de interés.

\section{Antecedentes nacionales}

En el contexto colombiano, también se han encontrado algunos proyectos que involucran el entretenimiento cultural, entre los cuales se encuentran: La Casa Museo Otraparte ubicada en Envigado Antioquia. Esta ha sido objeto de estudio para la implementación de realidad aumentada en el museo. Allí, como primera medida, seleccionan marcadores o imágenes, que el usuario puede visualizar en 3D. Para la aplicación se utilizó el software Artoolkit; además las imágenes son textos escritos por Fernando González con el fin de que el visitante no se conforme con visualizar gráficos, sino también que se motive por la lectura de los libros (Paez Martínez, pág. 9). 
Para el estudio de La Casa Museo Otraparte, se requirió

de la participación de 45 visitantes y dos (2) funcionarios, donde los usuarios disponían de la aplicación en realidad aumentada de manera libre y gratuita. La investigadora Luz Andrea Páez Martínez (s.f.) comentó que ha sido de gran interés y curiosidad para el público además de exponerlo como una necesidad para llamar la atención de más visitantes.

La tecnología en realidad aumentada, también se promovió en el Museo Arqueológico en la ciudad de Barranquilla durante el año 2015. Sin embargo, en este caso la aplicación se crea por medio de unas gafas con aplicación en RA, donde se busca que el público visitante pueda realizar un recorrido interactivo y lúdico por los espacios del museo. Esta aplicación fue desarrollada por un estudiante de ingeniería de sistemas de la Universidad del Norte en Barranquilla.

\section{Antecedentes locales}

Algunos avances realizados en la ciudad de Bogotá en cuanto a realidad aumentada en temas de turismo se presentan a continuación: con la presentación fotográfica del Parque Arqueológico de San Agustín realizado en los años 2013-2014, exposición que fue denominada como "el silencio de los ídolos", el Museo Nacional en la ciudad de Bogotá utilizó tecnología en realidad aumentada. Para esto, usaron teléfonos celulares y tabletas que brindaban información interactiva a visitantes y turistas sobre la conservación de texturas, colores etc., en el bosque de las estatuas (Museo Nacional de Colombia, 2014).

Asimismo, el Instituto Distrital de Turismo, en la ciudad de Bogotá, propuso la creación de una guía digital en realidad aumentada por medio de la aplicación móvil Soundwalkrs. 
Lo anterior, para permitir a los turistas recrear imágenes de lugares como museos, restaurantes, planes recreativos, entre otros. Adicional a ello, también tiene la posibilidad utilizar herramientas auditivas que brinden la opción de escuchar la información sobre cada uno de estos lugares.

\section{Marco de referencia}

Para una mejor comprensión de la presente investigación, a continuación se relacionan los que son considerados como conceptos y definiciones principales que hacen parte del proceso de construcción y desarrollo de la app.

\section{Realidad aumentada}

La realidad aumentada es un término que apareció hace muy poco tiempo. Aunque actualmente ha estado involucrándose en distintas áreas del conocimiento, aún sigue fuertemente adherida al concepto de realidad virtual. Esto se debe a que ambos presentan características similares a pesar de que se traten de tecnologías diferentes.

Podemos decir que el termino de realidad aumentada tiene sus orígenes de los postulados teóricos de establecidos en los trabajos de Ronald Azuma. Este define la realidad aumentada como una variación de los entornos virtuales, o realidad virtual como se conoce comúnmente (Ruiz Torres, 2013). A diferencia de la realidad virtual, que proporciona al usuario un entorno totalmente ficticio que lo separa totalmente del mundo real, la realidad aumentada da la posibilidad de que el usuario visualice el entorno real al que se le suman objetos virtuales. En este caso, la realidad aumentada permite que ambos convivan en el mismo espacio de forma simultánea. 
Una de las características principales es que los objetos virtuales ayudan al usuario a realizar labores del mundo real, estos proporcionan información concreta que el usuario no puede detectar de forma directa con sus propios sentidos. Además, es necesario afirmar que la realidad aumentada no se rige estrictamente a lo visual. Esta abre espacios para poder adaptarse a otros sentidos como el oído y el tacto (Ruiz Torres, 2013).

\section{Android (Sistema Operativo)}

Android es un sistema operativo que en sus inicios fue diseñado, únicamente, para teléfonos inteligentes (Smartphone). Sin embargo, en la actualidad es instalado tanto en smatphones como en múltiples dispositivos capaces de soportarlo (tal es el caso de tabletas, televisores, mini ordenadores entre otros). Nació en el año 2003, en una empresa de bajo perfil Ilamada Android Inc. Fundada por Andy Rubin, Chris White, Nick Sears y Rich Miner, esta empresa se encontraba ubicada en la ciudad de California.

No fue sino hasta el año 2005 cuando Android pasó del anonimato a ser el sistema operativo más popular entre las compañías fabricantes de teléfonos inteligentes. Lo anterior gracias a que Google lo compró, nombrando a Andy Rubin como jefe del departamento de desarrollo de esta plataforma. Ya finalizando el 2007 fue el lanzamiento de la primera versión de Android que a su vez fue acompañado por el Software Development Kit (SDK) por la Open Handset Alliance. Esto permitiría que los programadores comenzaran a hacer aplicaciones dirigidas específicamente a este sistema operativo. 
Posteriormente, en el año 2011, es anunciada su versión 3.0. Su principal particularidad fue que estaba mejorada y adaptada únicamente para tabletas, más no para teléfonos móviles. A pesar de la popularidad de Android, entre los fabricantes de dispositivos tecnológicos y la preferencia de los usuarios, este fue reprochado en diversas oportunidades por los problemas presentados que, en su mayoría, se trataban de requisitos de hardware de las nuevas versiones o porque los dispositivos antiguos no soportaban las versiones actualizadas.

Entre las principales características que hacen a Android un sistema operativo único y especial, podemos decir que es abierta, gratuita; posibilita a los fabricantes adoptar este sistema operativo a sus dispositivos móviles sin pagar y a los programadores que no necesitan hacer contrato con un fabricante específico.

\section{Autodesk Maya}

Autodesk Maya es un software de renderización, simulación, modelado y animación en 3D, que ofrece un conjunto de herramientas muy potente generalmente son utilizadas para crear animaciones, ambientes o entornos, gráficos de movimientos, realidad virtual y personajes. (Autodesk, 2017)

\section{Unity}

Es una plataforma para crear video juegos y aplicaciones para dispositivos móviles en 2D, 3D, realidad aumentada y realidad virtual. Cuenta con un poderoso motor gráfico totalmente apto para llevar a cabo cualquier idea que se pase por la mente, a parte del fácil desarrollo de video juegos y apps, 
Unity ofrece unos servicios que van dirigidos a la comprensión del público tales como:

- Unity Ads

- Unity Analytics

- Unity Collaborate

- Unity Cloud Build

Actualmente Unity es el motor más popular entre los desarrolladores de video juegos con el 34\% de juegos creados de 1000. (Unity Technologies, 2017)

\section{Vuforia}

Es un SDK (Software Development Kit) que permite construir aplicaciones para dispositivos móviles en realidad aumentada, como características principales de una aplicación realizada con Vuforia podemos decir que ofrece reconocimiento de texto, imágenes, gran amplitud de tracking, rápida detección de targets, este SDK está disponible para los sistemas operativos más comunes que existen actualmente como Linux, mac y Windows, además hablando de dispositivos móviles existe compatibilidad con los y Android (Cruz, 2017).

\section{Marcadores}

Los marcadores son imágenes que pueden ser reconocidas fácilmente por una aplicación que utilice Realidad Aumentada (Craig Dr., 2013), permite que elementos digitales tales como videos, imágenes, audios y objetos tridimensionales sean incorporados en un entorno real a través de la cámara del dispositivo móvil en el que esté instalada la aplicación. 
Metodología

\section{Delimitación del área}

La ciudad de Bogotá cuenta con una diversidad de lugares de interés turístico-cultural. Debido a esto, se hace necesario resaltar que la localidad de Santa Fe es una de las localidades con más sitios de interés dentro de su área. Una vez dicho esto, se entiende porqué se toma dicha localidad como base para el desarrollo de la aplicación. Así, se tiene en cuenta una fracción de terreno que está comprendido entre la Calle 39 hasta la Calle 13, en sentido norte-sur y desde la Carrera 14 (Avenida Caracas) hasta el santuario de Monserrate, ubicado en la cima de los cerros orientales de la capital, en sentido occidente-oriente.

Figura 1. Localización específica del proyecto.

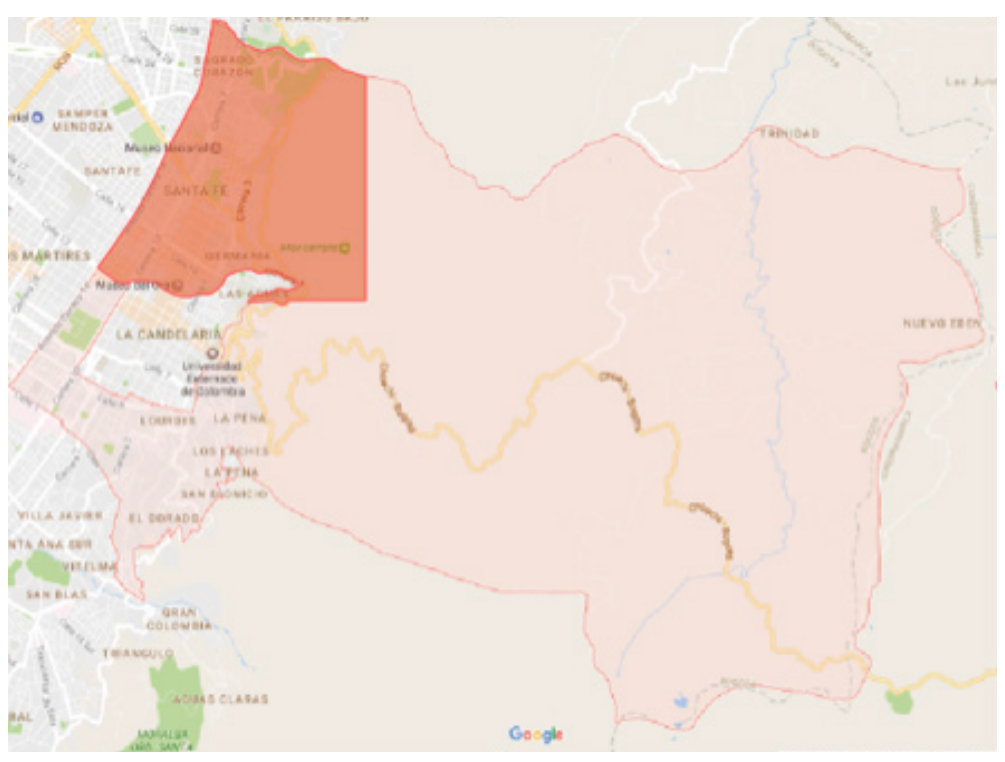

Fuente: Google Maps. 
Como la localidad de Santa Fe es un foco cultural y turísti$\mathrm{co}$, y aprovechando la proximidad que hay entre cada uno de sus lugares turísticos, se hace la selección de cinco (5) de estos para la recolección de información y desarrollo del modelado tridimensional de cada uno de estos e integrarlos posteriormente a la aplicación, dicho esto los lugares seleccionados son:

- Planetario Distrital de Bogotá

- Mirador Torre Colpatria

- Museo Nacional de Colombia

- Museo del Oro

- Basílica Del Señor Caído de Monserrate

Figura 2. Localización de los sitios turísticos.

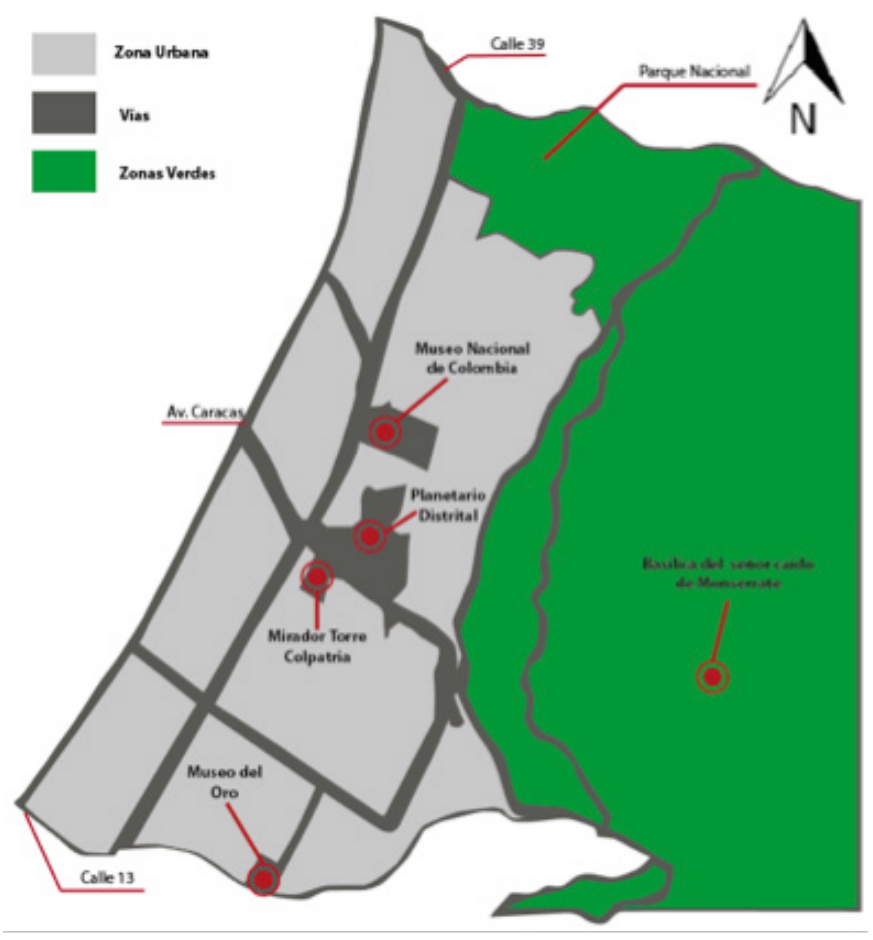

Fuente: elaboración propia. 


\section{Diseño y bocetación de escenarios}

La aplicación, gráficamente, cuenta con dos escenarios en 3D que el usuario puede intercambiar a voluntad según sea su agrado. En el primer escenario, el área del proyecto es representada de una forma urbana y realista, con elementos arquitectónicosy naturales con baja cantidad de polígonos (Low Poly).

Figura 3. Boceto Primer Escenario (Entorno Urbano).

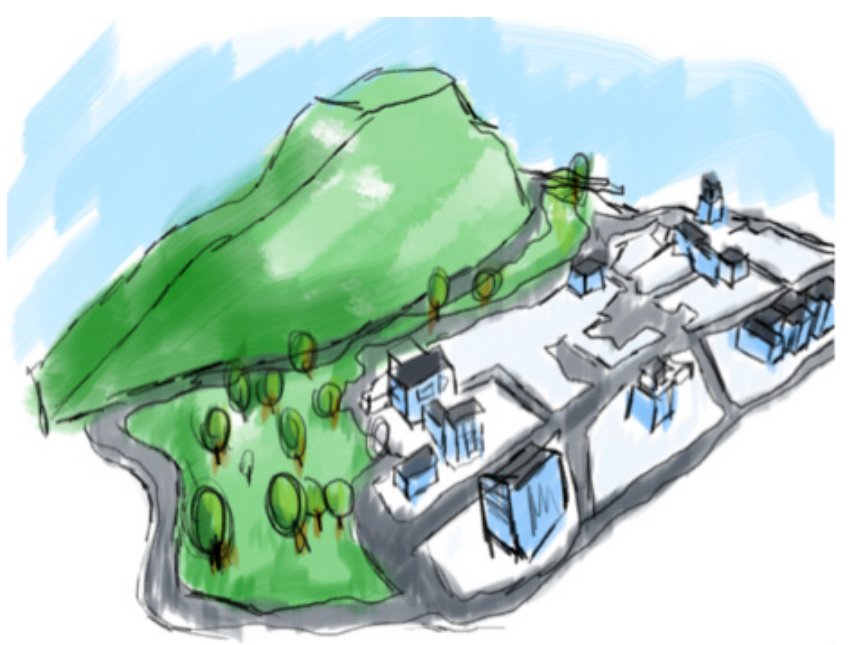

Fuente: elaboración propia.

El segundo escenario tiene un aspecto de juego de video de tipo aventura, con elementos arquitectónicos poco comunes y vegetación de apariencia fantasiosa.

Figura 4. Boceto Segundo Escenario (Entorno Fantástico).

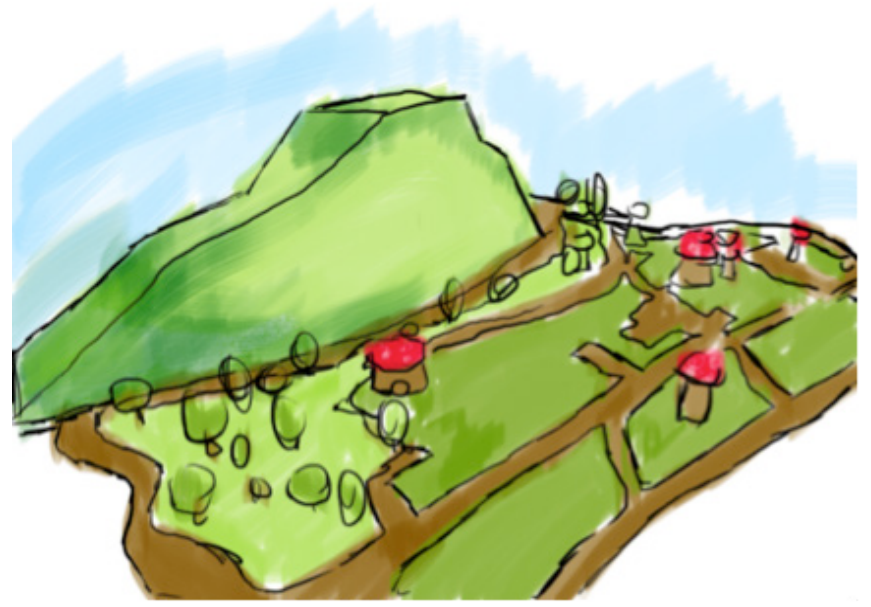

Fuente: elaboración propia. 
Características del personaje

La definición de la apariencia física del personaje es de vital importancia para poder tener un mejor flujo de trabajo en la realización de los bocetos, ilustraciones y modelado tridimensional del mismo. En ese sentido, para que el personaje adopte una apariencia que esté fuera del común de la población de la capital, sus características físicas se inclinan hacia unos rasgos europeos, es decir con piel blanca, cabello rubio. Además, a esto se incluyen elementos característicos tales como lentes oscuros, gorra y ropa deportiva con colores llamativos.

Descripción física del personaje

Es importante darle a este personaje una apariencia tierna, esto hará que los usuarios de cualquier edad tengan afinidad y simpatía con él. Cabe resaltar que para dar esta sensación de ternura, hay características físicas que van a ayudar con este propósito. Ahora bien, sabiendo que el personaje debe tener el aspecto de un niño o bebé, la cabeza deberá tener un tamaño mayor a los cánones conocidos de las proporciones de la anatomía humana realista. Es decir, la cabeza debe ser del mismo tamaño del resto del cuerpo. Asimismo, los ojos deben tener un tamaño mayor. En este caso, si nuestro personaje porta lentes oscuros, estos tendrán un tamaño que abarcará un cuarto (1/4) del tamaño total de su rostro.

Boceto del personaje

Una vez establecidas las características principales que debe tener el personaje, se procede a realizar los bocetos correspondientes en las distintas vistas (frente, perfil, trasera y tres cuartos). Estas vistas serán de gran ayuda e importancia para el posterior desarrollo tridimensional del mismo. 
Figura 5. Boceto Personaje Vistas.
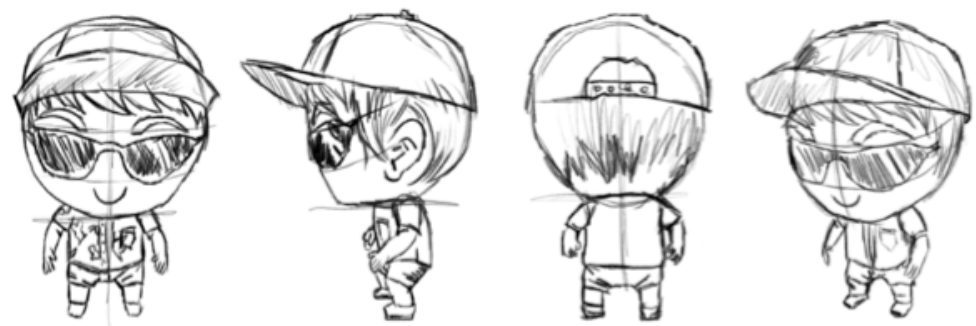

Fuente: elaboración propia.

Con la estructura del personaje definida, se procede a establecer una paleta de colores que lo represente. Esta tiene colores saturados de alto impacto para una apta visualización del personaje una vez este la aplicación finalizada.

Figura 6. Paleta de Colores Personaje.
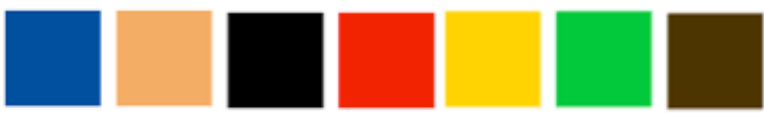

Fuente: elaboración propia.

Una vez definido el boceto y la paleta de colores del personaje, es necesario hacer una ilustración vectorial de cada una de las vistas antes referenciadas. Esto puede ser importante para su utilización en posible material gráfico, ya sea impreso o digital, que pueda requerirse con posterioridad. Esta ilustración se ha de realizar en el software de dibujo vectorial Adobe Illustrator (Adobe Systems, 2017).

Figura 7. Ilustración vectorial del personaje vistas de Frente y tres cuartos.

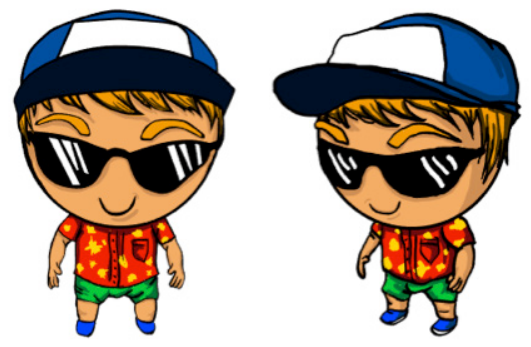

Fuente: elaboración propia. 
Diseño de imagen de la aplicación

En primera instancia, se realizan propuestas del nombre y logotipo que va a llevar la aplicación móvil. Una vez aclarado lo anterior, para el nombre se propone la unión de dos palabras que representen la intención con la que se ha realizado el proyecto y el punto exacto al cual va dirigido. Así, las palabras seleccionadas fueron "Bogotá" (enfocando de esta manera que el proyecto está dirigido a la capital) y "Viva" (como representación de la intención que tiene la realización de esta aplicación: mantener a la ciudad y a sus lugares representativos vivos culturalmente en la memoria de la sociedad).

\section{Colores representativos}

Los colores seleccionados en el logotipo final de la aplicación son el rojo y el amarillo, colores representativos de la bandera de la capital colombiana.

\section{Figura 8. Paleta de Colores Logotipo.}

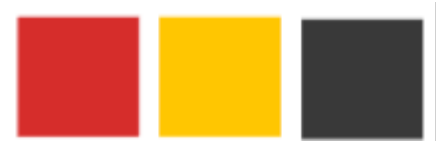

Fuente: elaboración propia.

Diseño final imagotipo

Con el fin de complementar el símbolo anteriormente relacionado, se escribe el nombre de la aplicación junto a la palabra "Beta" que indica que la aplicación es un prototipo en desarrollo. Todo esto estará escrito con la tipografía Coolvetica y junto al símbolo conforman el logotipo final. Este va a ser importante para el reconocimiento inmediato y rápido del proyecto.

Este imagotipo es una herramienta con la cual el usuario puede asociar a la aplicación con un sentido de pertenencia marcado hacia la ciudad y sus sitios turísticos. 
Figura 9. Imagotipo Final.

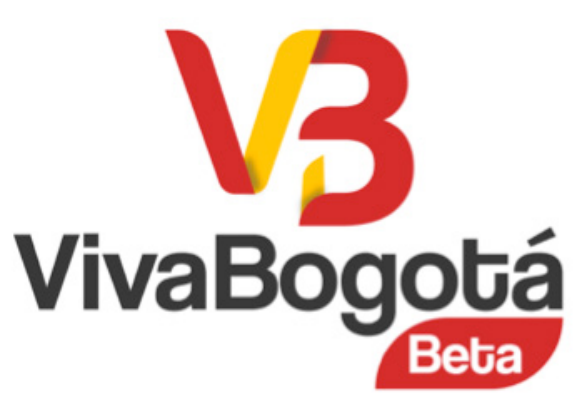

Fuente: elaboración propia.

Diseño de marcador (Target)

Hay que dejar claro que para que la aplicación en realidad aumentada funcione adecuadamente, es necesario tener un código o marcador (Markers). Este marcador va a ser registrado por la cámara del dispositivo móvil en el cual está instalada la aplicación. Para que el marcador funcione adecuadamente, debe tener un alto nivel de tracking, que es la capacidad que tiene la imagen de mantener el objeto digital en realidad aumentada en pantalla sin que sea inestable o se pierda.

En el proceso de construcción de la aplicación, Vuforia nos va a indicar si la imagen tiene, o no, un nivel apropiado de tracking. Dicho esto, cabe aclarar que para alcanzar un nivel de tracking optimo, la imagen debe tener dos características principales. Estas son la variedad de contraste entre tonos oscuros y claros y la gran cantidad de puntas o ángulos que mantengan un registro constante.

Hay que mencionar que, para la presente investigación, se utiliza el logotipo como una base en el diseño del marcador que va a servir para la visualización de la aplicación, teniendo claro que únicamente el logotipo no proporciona el nivel de tracking requerido para una visualización 
plena del producto. Así, se procede a agregar elementos

geométricos alrededor del mismo. Dichos elementos tienen los colores característicos de la bandera de la ciudad (Rojo y Amarillo), con diferencias tonales que proporcionan alto contraste. De esta forma, se garantiza que sea totalmente apto para el buen funcionamiento de la aplicación.

Figura 10. Diseño del Marcador.

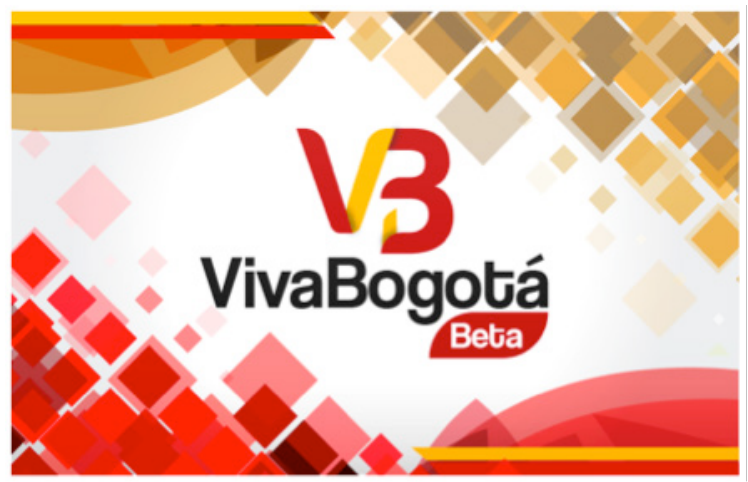

Fuente: elaboración propia.

\section{Diseño de la interface o aplicación}

Con el fin de darle relevancia a los elementos principales de la aplicación, se hizo necesario ubicar un panel lateral que va a contener los elementos del menú principal. De esta forma proporcionará al usuario una apariencia intuitiva y de fácil comprensión. Así, le permitirá tener un acceso efectivo a la información y a diferentes elementos que enlazan los escenarios mencionados con los contenidos.

Para mantener una unidad gráfica en la totalidad de los elementos que componen este proyecto, se utilizaron varios de los colores antes propuestos para el personaje, estos son: 
-Azul

-Blanco

- Negro

El azul es el color principal de los paneles que va a contener tanto el menú principal como toda la información específica de cada uno de los sitios turísticos, el blanco y el negro serán utilizados como un contraste entre textos según se necesite.

Figura 11. Colores de la Interface.
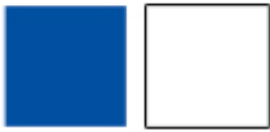

Fuente: elaboración propia.

\section{Pantalla inicial}

La estructura de la pantalla inicial de la App está compuesta por dos paneles, uno de ellos siempre va a poder ser visualizado por el usuario en el costado izquierdo de la pantalla. Este panel contiene el menú principal y el logotipo representativo de la aplicación. En el costado derecho está ubicado un panel que solo se hará visible cuando el usuario desee ver la información de los créditos e instrucciones. Cuando el panel de la derecha este inactivo, se va a mostrar una animación de movimiento de cámara.

Figura 12. Boceto Pantalla Inicial.

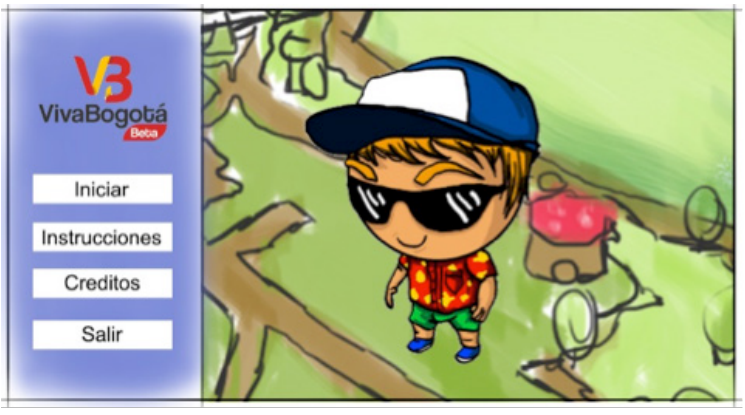

Fuente: elaboración propia. 
Cuando la aplicación esté en uso y activa, se va a utilizar una interface similar a la de la pantalla inicial, manteniendo el panel derecho que, en este caso, se hará visible cuando el personaje entre a un área que active la visualización de la información de cada sitio turístico. Además de esto, el usuario va a poder visualizar en todo momento tres botones que le van a permitir el traslado de un escenario a otro, regresar al menú de la pantalla inicial o activar el sonido ambiente de la aplicación. Ya en la parte inferior izquierda está situado el Joystick que va a permitir al usuario controlar el personaje movilizándolo por todo el escenario.

Figura 13. Boceto Interfase con la aplicación activa.

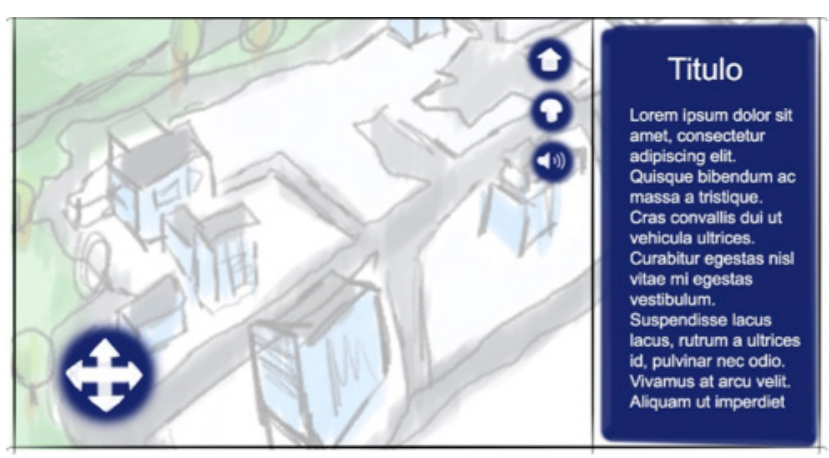

Fuente: elaboración propia.

\section{Desarrollo tridimensional}

\section{Elementos arquitectónicos}

Según la selección de los cinco sitios turísticos ya mencionados, y en los cuales se enfoca la realización del presente artículo, se inicia la realización de modelado tridimensional de cada uno de estos. El objetivo principal de este procedimiento es mantener un número bajo de polígonos (Low Poly), con el propósito de disminuir el peso de los mismos y garantizar un óptimo desempeño de la aplicación una vez esté terminada. 
Para el desarrollo apropiado de estos modelos en 3D fue necesaria la utilización de material fotográfico de los lugares de interés, en distintas perspectivas, que sirvieran como referencia, en el proceso completo del modelado (además del uso de Google Maps). Esta labor fue realizada en el software de diseño tridimensional de la compañía Autodesk (2017) en su licencia para estudiantes.

Figura 14. Modelo Tridimensional Finalizado Planetario Distrital.

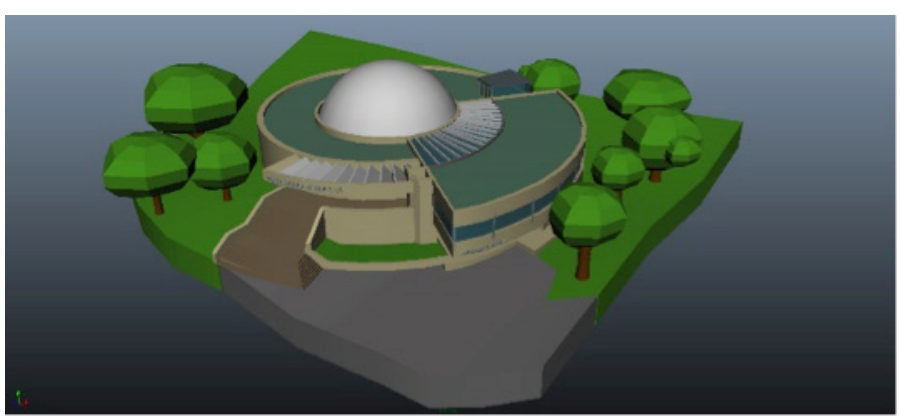

Fuente: elaboración propia

Figura 15. Modelo Tridimensional Finalizado Basilica Del Señor Caido de Monserrate.

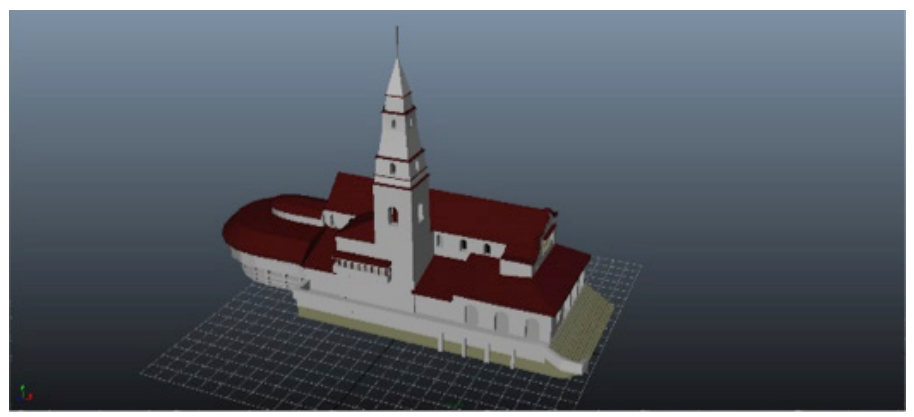

Fuente: elaboración propia.

Tener el área en la cual se centra la aplicación en forma tridimensional es indispensable para la construcción y diseño final de los escenarios. Por lo anterior, el primer paso es hacer el dibujo del área en el software Adobe Illustrator (Adobe Systems, 2017) de forma independiente, es decir un grafico para el área en total, otro para la parte urbana y otro para las áreas de vegetación o césped. 
Figura 16. Gráfico vectorial que muestra cada área principal del escenario.
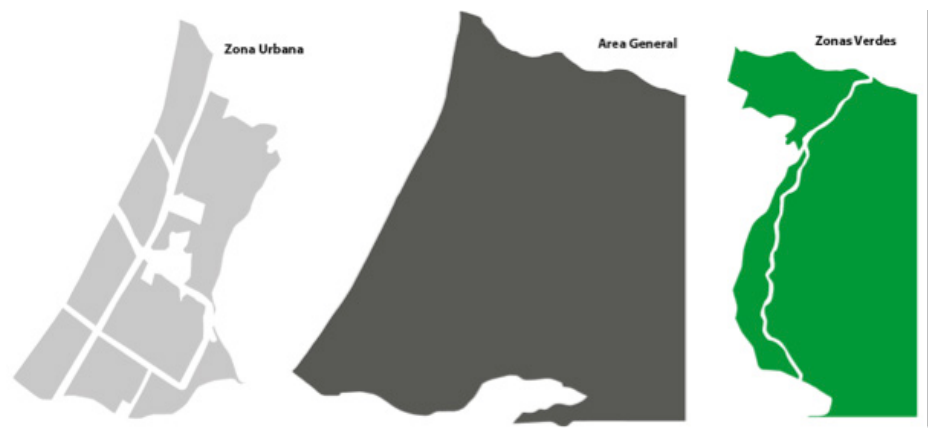

Fuente: elaboración propia.

Después de tener los elementos vectorizados, se guardan en la versión número ocho (8) de Adobe Illustrator para posteriormente ser importados a Autodesk Maya. Una vez los gráficos vectoriales se importen a Maya, van a tener una apariencia 3D que va a servir para su posterior integración a Unity.

Figura 17. Despiece de áreas en 3D, Autodesk Maya.

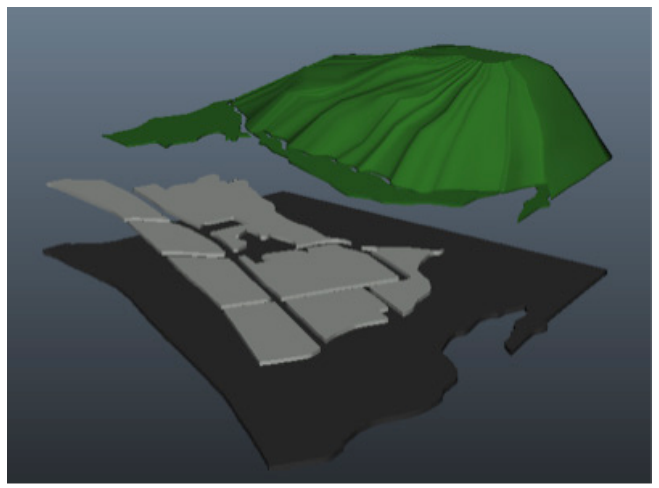

Fuente: Autodesk.

\section{Personaje}

De la mano con la realización del modelado tridimensional del personaje, es necesario resaltar que se aprovechó la tienda de Unity, "Unity Asset Store" (Unity Technologies, 2017), para descargar un modelo tridimensional que en su forma se adapta a las características físicas de nuestro turista. El modelado que se descargó se denomina "Chibi Mummy", este personaje utilizaba una textura la cual fue modificada para dar al personaje una apariencia apropiada para la ejecución de este proyecto. 
Figura 18. Comparación personaje "Chibi Mummy" con el producto final utilizado para la Aplicación.
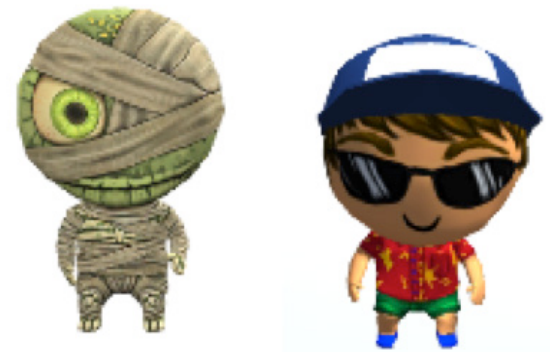

Fuente: Unity Technologies \& elaboración propia

\section{Construcción de la aplicación}

Unity es el software base para la construcción de la aplicación al cual fue integrado los pack de propiedades de Android (SDK), Java (JDK) y Vuforia, indispensable para la visualización de los objetos en realidad aumentada. Todos estos elementos son esenciales para la compilación final de la aplicación y su óptimo funcionamiento.

Montaje de escenarios

En la construcción de la aplicación se generaron tres (3) escenas en Unity en las cuales se integraron los modelados tridimensionales, tanto arquitectónicos como el personaje; los paneles informativos y unos assest gratuitos descargados de la Unity Asset Store. Los elementos de esos assets permitieron construir cada uno de los escenarios de acuerdo a las características mencionadas anteriormente. Así, las escenas compuestas en unity quedan definidas de la siguiente manera:

Escena 0: pantalla de inicio

Acorde con lo establecido en la etapa de bocetación de la interface, se integraron los paneles con el logotipo de la aplicación y los botones del menú principal. 
Figura 19. Pantalla de Inicio Finalizada.

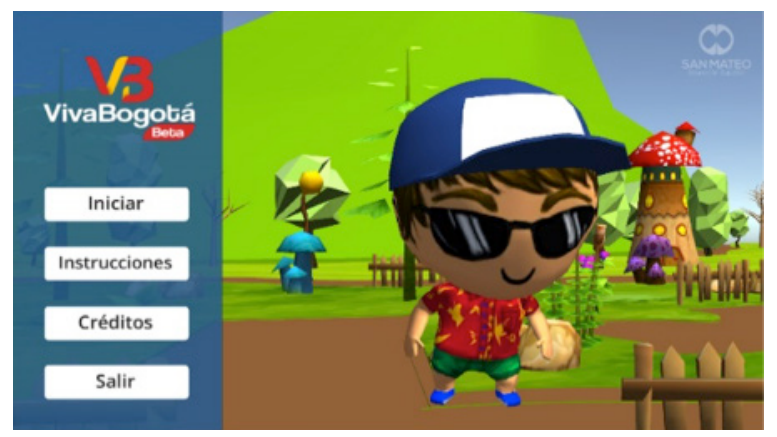

Fuente: elaboración propia.

\section{Escena 1: escenario entorno urbano}

Una vez se inicie la aplicación, por medio del botón "Iniciar", ubicado en la escena 0 , y el posterior registro del marcado con la cámara del dispositivo móvil, se va a cargar por defecto el entorno urbano. La intención es representar de forma realista las características propias de la localidad de Santa Fe. Este escenario fue ambientado con la utilización de dos Assets de elementos prefabricados, llamados "Cartoon City" y "Low Poly Styled Trees", en los que se encontraban elementos de mobiliario urbano y estructuras arquitectónicas de estilo cartoon.

Figura 20. Escenario Urbano Finalizado.

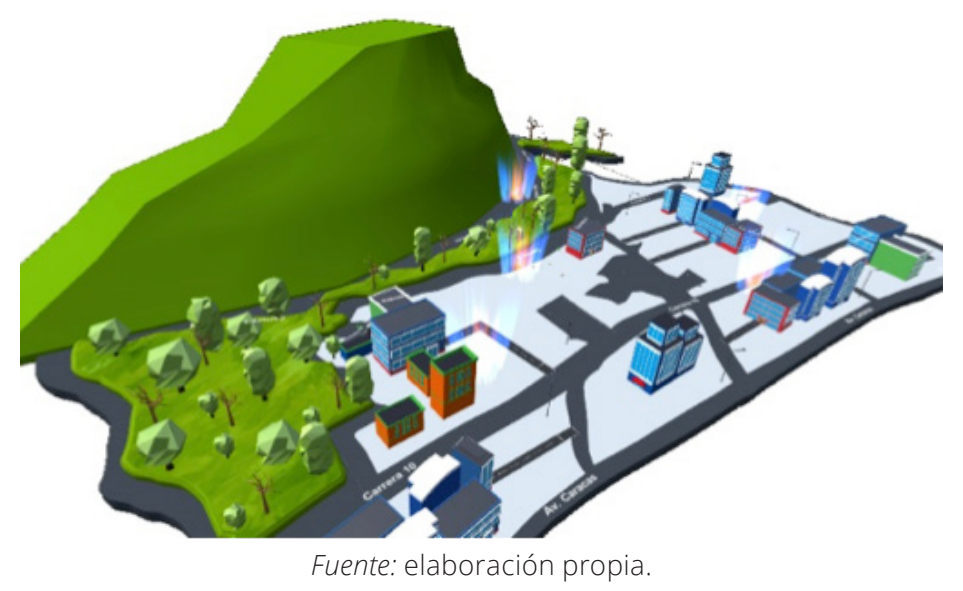

Escena 2: escenario entorno fantástico

A diferencia del entorno urbano, el segundo escenario está ambientado con elementos propios de un video juego de estilo aventura, con edificaciones poco comunes en forma 
de hongos y vegetación poco tradicional. Es necesario mencionar que para la correcta ambientación de este escenario fue necesaria la descarga de dos Assets de Unity llamados "Mushroom Land y Low Poly Styled Trees"

Figura 21. Escenario Fantástico Finalizado.

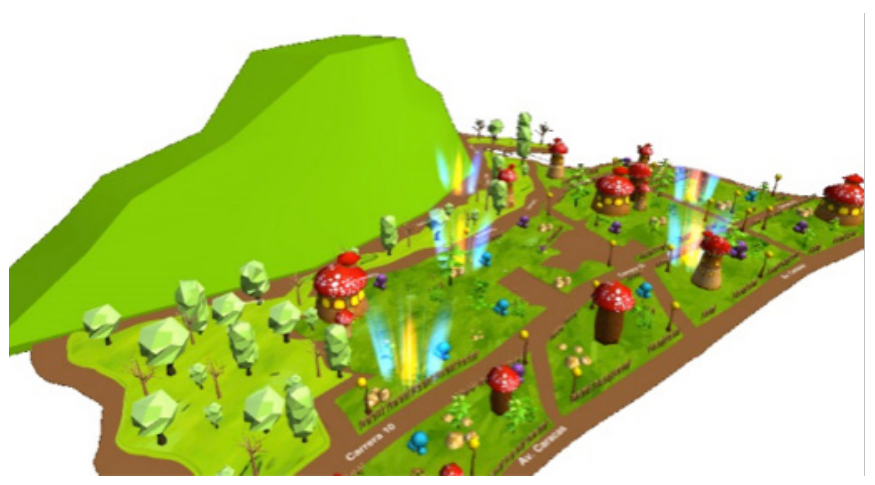

Fuente: elaboración propia.

\section{Integración de la interface con los escenarios}

Cuando el usuario esté manipulando al personaje por los escenarios, la visualización de la interface se va a modificar pasando de lo plenamente interactivo a un contexto informativo. Cabe aclarar que los botones de joystick, regreso al menú inicial y activación del sonido se completaron según el boceto propuesto con anterioridad.

Figura 22. Integración escenarios e Interface.

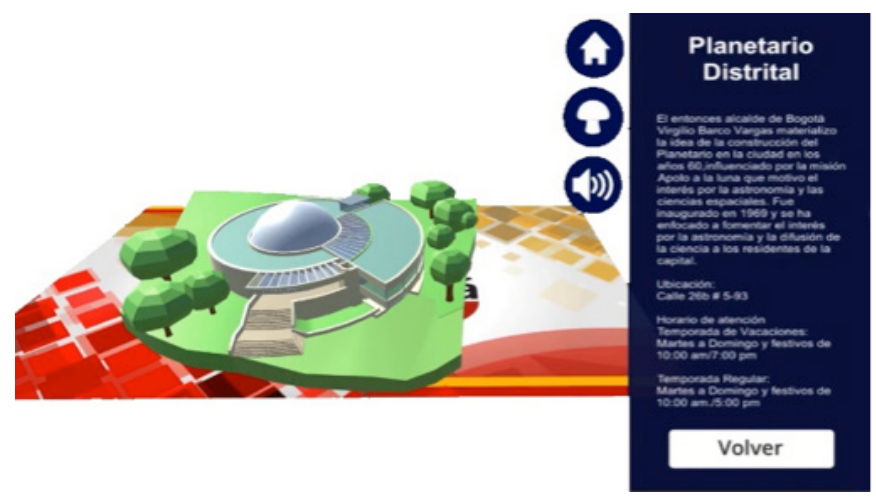

Fuente: elaboración propia. 
Características Botón Ver

En el proceso de construcción de la aplicación, se hizo necesaria la realización de un botón que permitiera al usuario aislar el modelado tridimensional con el cual esté realizando interacción. Esto con el objetivo de brindar una mejor visualización del elemento en cuestión.

Figura 23. Vista Aislada del Planetario Distrital.

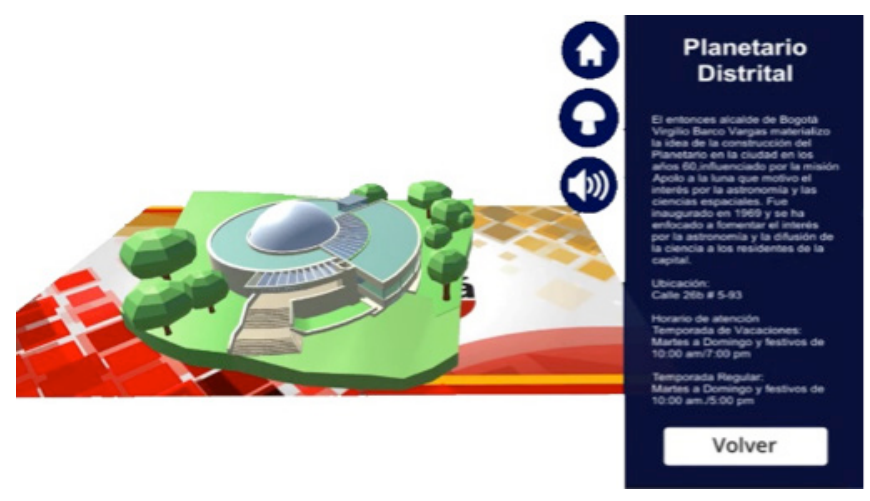

Fuente: elaboración propia.

\section{Programación y compilación de la app}

Con el fin de lograr una correcta integración de todos los elementos, asi como la correcta y ordenada visualización de cada uno de ellos, fue necesaria la programación de cada uno de estos con un entorno de desarrollo programación con código integrado a Unity llamado "Mono Develop", utilizando los lenguajes de programación C Sharp y Javascript.

Si hablamos de la compilación de la aplicación tenemos que mencionar a Unity. Este software nos da la posibilidad de compilar para diversidad de plataformas como Windows, Mac, los, Vita, Psp y Android. Según lo planteado, desde el inicio de la aplicación se realiza la compilación final para todos los dispositivo móviles que sean operados con Android. 


\section{Discusión}

Luego de finalizada la aplicación, y comprobado su funcionamiento, se presentó el resultado al artista 3D y docente Juan Sebastián Wilches, un profesional con amplia trayectoria en el desarrollo de aplicaciones interactivas que utilizan la tecnología de realidad aumentada. Luego de poner a prueba la aplicación realizó un análisis objetivo con puntos a favor y posibles modificaciones que podría tener a futuro para mejorar su funcionalidad.

\section{Aspectos positivos}

Resaltó de forma positiva la correcta funcionalidad de la aplicación en cuestión de interactividad. También mencionó el buen resultado en cuestión de diagramación e impacto generado desde el menú inicial, el cual le resulto muy atractivo e interesante. Consideró acertado el aprovechamiento de los recursos como el Joystick, los botones y la presentación de la información.

En cuanto al desarrollo de los modelados, consideró excelente el desarrollo final de los mismos. Además, resaltó la también la característica de poder ser aislados para su visualización.

\section{Aspectos por mejorar}

El docente hizo la recomendación de realizar una prueba en dispositivos con distintas resoluciones de pantalla puesto que algunos elementos tienden a pixelarse. Consideró imprescindible desactivar los escenarios al momento de aislar los elementos arquitectónicos, puesto que este se aleja pero se oculta, generando un peso gráfico extra mientras se está interactuando. Por último, creyó oportuno que se revisaran la cantidad de polígonos integrados pues hubo momentos en que la aplicación comenzó a disminuir su rendimiento. 


\section{Conclusiones}

La investigación de los antecedentes permitió evidenciar que actualmente no existe una aplicación para dispositivos móviles enfocada al turismo de la capital que utilice la Realidad Aumentada para proporcionar una interacción y una experiencia novedosa a los turistas.

Gracias a la incorporación de las Tecnologías de la Información y la Comunicación (TIC) a los distintos procesos que hacen parte esencial para el desarrollo de una ciudad, podemos decir que la Realidad Aumentada es una tecnología novedosa que apoya al turismo en la localidad de Santa Fe y sus lugares de interés cultural.

Fue un acierto la realización de los modelados tridimensionales en bajo poligonaje (Low Poly), El rendimiento de la aplicación es apropiado, permitiendo una correcta visualización de todos los elementos que la integran.

Debido a las dimensiones y cantidad de lugares de interés turístico-culturales que tiene la ciudad de Bogotá, no es viable realizar una aplicación que la involucre en su totalidad. Para esto, es mejor desarrollar una aplicación para cada una de las localidades.

Si se quisiera desarrollar una aplicación similar a la presentada en este proyecto pero que abarque un área mayor, se recomienda la utilización de la tecnología de realidad virtual, que también puede ser utilizada en dispositivos móviles de alta gama.

El desarrollo de la aplicación móvil es viable pues es una idea novedosa que actualmente no tiene un competidor directo en el uso de la tecnología de realidad aumentada y tampoco en el área seleccionada. Aparte de lo anterior, financieramente no tiene costos elevados pues se realizó con licencias gratuitas. 


\section{Lista de referencias}

Adobe Systems. (2017). Crea hermosas ilustraciones vectoriales. Obtenido de Adobe: http://www.adobe.com/la/products/illustrator.html

Autodesk. (2017). Hágalo con el software de animación por computadora Maya. Obtenido de Autodesk Latinoamerica: https://latinoamerica.autodesk.com/products/maya/overview

Centro Educativo IES. (2015). Proyecto de realidad aumentada y audioguías "En Tierra de Gigantes". Obtenido de Campo de Criptana: http://campodecriptana.weebly.com/ uploads/2/0/3/5/2035264/proyecto_entierradegigantes. pdf

Craig Dr., A. B. (2013). Understanding Augmented Reality: Concepts and Applications. Oxford: Elsevier Science \& Technology.

Cruz, A. (2017). Realidad Aumentada con Vuforia. Obtenido de Desarrollo Libre: http://www.desarrollolibre.net/blog/ tema/73/android/realidad-aumentada-con-vuforia\#.WSoH2es1-Uk

Museo Nacional de Colombia. (2014). El silencio de los idolos. Informe de exposicion Temporal.

Paez Martínez, L. A. (s.f.). Realidad aumentada para la diseminacion de información cultural. Recuperado el 27 de 05 de 2017, de Universitat Oberta de Catalunya: http://openaccess.uoc.edu/webapps/o2/bitstream/10609/42781/6/ IpaezmTFM0615memoria.pdf

Ruiz Torres, D. (2013). La Realidad Aumentada y su aplicación en el patrimonio cultural. Guijón: Ediciones Trea.

Unity Technologies. (2017). Todo lo que necesitas para tener éxito en los juegos y en VR/AR. Obtenido de Unity 3D: https://unity3d.com/es 